\section{JAPANESE WHALING INDUSTRY}

The British Commissioner at Yokohama reports that whaling in Japan waters is carried on under license from the Government, the number of whalers being restricted to 30 , of which one company owns 24 . There seems little prospect of the number of vessels being increased at present.

The whalers are steam vessels of about 100 to 150 tons and are built after the Norwegian whaling type. The boats seldom venture out more than 50 or 60 miles from land and remain out a day or so at a time. The varieties of whale mostly caught are the sperm and sulfur bottom.

According to the report, the estimated number of whales caught in 1916 was $I, 400$, valued at $\$ I, 150,000$, compared with I,7 IO, valued at $\$$ I, 064,809, in I 9 I 5 , and I,700 worth $\$$ I $, 412,465$ in IgI4. The approximate yield of whale oil in Japan is stated to have been 2,500 tons in I I I $3,4,500$ tons in I $19 \mathrm{I} 4$ and 5,500 tons in $1915 .-\mathrm{M}$.

\section{ASBESTOS-CEMENT ROOFING}

In the course of the last I 2 months, says the Times Engineer. ing Supplement, No. $5 \mathrm{I} 2$, a factory has been built and equipped by the British Everite and Asbestilite Works, Lancashire, for the manufacture of asbestos-cement products, especially corrugated sheets for roofing, which in the past have been largely imported from abroad.

After being finely ground and freed from extraneous matter the asbestos, which acts as a reinforcing agent, is mixed with Portland cement in the proportion of about $I$ to 6 , and made into a kind of paste with water. This paste is then taken to a machine of the paper-making type, where, on a large revolving drum, it is formed into sheets or felts. After being trimmed to size, these sheets, if they are to be made into corrugated roofing, next have the corrugations impressed on them, the important condition of this operation being to ensure that the tops of the corrugations are as strong as other parts of the sheets. Finally, the sheets are subjected to a seasoning process.

The corrugations are made to the 3 -in. pitch, which is usual with corrugated iron sheeting, not to the $2^{1 / 2}$-in. foreign pitch, and they can therefore be used to repair roofs composed of corrugated iron sheets. One of the chief advantages claimed for them is durability and resistance to climatic conditions, especially to an acid-laden atmosphere which rapidly destroys corrugated iron; they are also fire-proof and poor conductors of heat.

The factory is well situated as regards supply of water, of which large quantities are required. The machinery is driven by electricity, current being obtained by means of a $220 \mathrm{H}$. P. National gas engine, and the power house is designed so that additional sets can be installed as the manufacture develops. $-M$.

\section{JAPANESE GELATINE AND GLUE}

The importation of gelatin and glue, says the Chemical Technology of Tokyo, had increased its amount to $\$ 500,000$, and the quick development of the paper-spinning, cloth-finishing, sweetsmaking and mateh industries has demanded more and more importation; but the manufacture of the gelatine and glue at home has also quickly developed. Research work has been begun at Tokyo, Osaka, Wakayama, Nara and Tokushima. Among the new establishments, the Takasago Kogyo Kabushiki Kwaisha, the largest, is going to produce $10,000 \mathrm{lbs}$, of gelatine and 15,000 lbs. of glue monthly. This amount will well fulfil the home demand. Furthermore, the Osaka Alkali Company is going to start the manufacture of gelatine, while the Mitsubiski Company is financing a big firm at Kakogawa. The big firms will certainly bring a big surplus against the home trade, and so it is anticipated that there will be certain panic in the near future unless a proper market is found.-M.

\section{NEW PLASTIC MATERIAL}

India Rubber Journal, 53 (1917), 2, describes a French invention for a new plastic material which is non-inflammable and odorless. The material is obtained by transforming gelatines, glues and such substances of animal origin by suitable chemical reagents, giving them plastic and malleable properties which allow them to be used industrially in a manner similar to natural products. The gelatines or glues are first melted in a water bath at a temperature of $90^{\circ} \mathrm{C}$. A decoction of hop flowers is then prepared and mixed with dilute oxalic or any dibasic acid of that series and the solution is added to the melted gelatines or glues in varying proportions according to the quality of the materials employed. The addition of this solution has the effect of rendering the gelatine more supple and of causing the impurities they contain to deposit at the bottom of the vessel. When the gelatines are liquefied they are poured out in the form of sheets or sticks of the desired thickness and left to dry in the cold air.

The coloring of the material is then proceeded with, natural or artificial dyes being employed. The sheets, when colored, are plunged into a bath of approximately the following composition: 25 to 35 per cent formaldehyde, 25 to 35 per cent water, 25 to 35 per cent alcohol and the rest composed of a mixture of oxalic acid, tannin and glycerine. The oxalic acid may be replaced by any other acid of that series. The plates should be left in this solution until the liquid has penetrated into the entire plastic mass. In the case of rich gelatines, the proportion of alcohol must be increased. The sheets when taken out of the bath are dried, preferably in hot air. The substance when suitably worked may serve for the manufacture of combs, buttons, brushes, etc., as an imitation of tortoise shell, horn, amber or ivory, and is unlike other cellulose products used in industry. in being absolutely non-inflammable and odorless.-.M.

\section{TUNGSTEN ORES IN RHODESIA}

According to an article in Mining Journal, II7 (1917), 4I6, occurrences of tungsten ore have been known for a considerable time in Rhodesia, though they have never been worked save in a desultory fashion. Prospecting was begun as far back as 1906 , but in 1909 all work was abandoned. Another attempt was made in 1912-13 and, during last year again, the demand for the material caused attention to be devoted to this locality. The occurrences, which are known, have been found close to the Essex Vale siding and I 6 reefs have been located, I I of which have been at one time or another worked and concentrates to the amount of 85 tons abtained. In addition to the reefs, there are also alluvial patches, but it does not appear that any extensive development has been done.

A report has recently been issued by the Rhodesian Geological Survey in which the geology and mineralization are discussed.

The mineral appears to be found entirely in quartz, similar to the ordinary vein quartz of the gold deposits. In one instance. at Tungsten Kopje, a stock-work deposit has been uncovered but, for the most part, the quartz is lenticular. Iarge bunches of wolfram crystals weighing in three instances 235, I 72 and I $57 \mathrm{lbs}$., have been found in the stock work while pieces up to $8 \mathrm{lbs}$, are not uncommon. Both wolfram and scheelite occur, the crystals being frequently intergrown. The alluvial appears to be in the nature of sheddings from the reefs and in some cases has served as an indicator of the original deposit. Tests in some of the alluvial deposits show from 2 to $8 \mathrm{lbs}$, per ton, excluding the large lumps of scheelite. Probably insufficient work has been done upon the reefs to permit of any average being hazarded of the grade in situ. There is also obvious lack of experience in regards to the ore. Considering how little Rhodesia has been prospected, except possibly for gold, these discoveries in the neighborhood of the railway may be regarded as encouragement for further investigations. $-\mathbf{M}$. 